\title{
Electric Power Supply Quality in ship systems: an overview
}

\section{J. Prousalidis*}

National Technical University of Athens (NTUA), Greece

E-mail:.jprousal@naval.ntua.gr

${ }^{*}$ Corresponding author

\section{E. Styvaktakis}

Hellenic Transmission System Operator (HTSO), Greece

E-mail: estyvaktakis@desmie.gr

\section{I.K. Hatzilau}

Hellenic Naval Academy (HNA), Greece

E-mail: ikx@snd.edu.gr

\section{F. Kanellos}

Hellenic Transmission System Operator (HTSO), Greece E-mail: fkanellos@desmie.gr

\section{S. Perros}

Hellenic Navy (HN), Greece

E-mail: sperros@yahoo.com

\section{E. Sofras}

National Technical University of Athens (NTUA), Greece E-mail: elsofras@yahoo.gr

\begin{abstract}
Power Supply Quality (PSQ) has become an important concern for ship electric systems. Thus, deviations of voltage from nominal values and wave-shapes could cause several problems onboard. Considering that ship system electrification eventually dominates according to the All Electric Ship concept, PSQ will be a key-factor of the normal operation, survivability and safety aboard. The paper provides a coherent description and categorisation of the PSQ phenomena (causes, consequences, characteristic parameters etc.) highlighting similarities and differences between terrestrial systems and ship systems in terms of these phenomena. This overview is enriched by cross-references to relevant standards applied in shipboard applications.
\end{abstract}

Keywords: Power Supply Quality; PSQ; standards; All Electric Ship; AES. 
Reference to this paper should be made as follows: Prousalidis, J., Styvaktakis, E., Hatzilau, I.K., Kanellos, F., Perros, S. and Sofras, E. (2008) 'Electric Power Supply Quality in ship systems: an overview', Int. J. Ocean Systems Management, Vol. 1, No. 1, pp.68-83.

Biographical notes: J. Prousalidis (Electrical Engineer from NTUA/1991, PhD from NTUA/1997). Assistant Professor at the School of Naval and Marine Engineering of National Technical University of Athens, dealing with electric energy systems and electric propulsion schemes on shipboard.

E. Styvaktakis (Electrical Engineer from NTUA/1995, MSc in Electrical Engineering from UMIST/1996, PhD from Chalmers/2002). He is currently with the Hellenic Transmission System Operator dealing with power system studies.

I.K. Hatzilau (Electrical and Mechanical Engineer from NTUA/1965, Dr-Ing from University of Stuttgart/1969). After few years in the industry, he joined the Academic Staff of Department of Electrical Engineering and Computer Science in HNA. He is representative of HN in NATO AC/141(NG/6)SG/4 dealing with warship-electric systems.

F. Kanellos (Electrical Engineer from NTUA/1998, PhD from NTUA/2003). He currently works as consultant engineer for General Secretary of Research and Technology of Greece.

S. Perros (Engineer Officer from the HNA/1984, MSc in Electrical Engineering from Naval Postgraduate School in Monterey California, (USA)/1992). After many years of service in $\mathrm{HN}$ warships, he is assigned now in HN General Staff. He is also an Associate of the Department of Electrical Engineering and Computer Science in HNA.

E. Sofras (Naval Architect and Marine Engineer from NTUA/2004). Currently, he is pursuing postgraduate studies as a PhD candidate at NTUA, dealing with electric power quality issues of ship electric networks.

\section{Introduction and background}

Power Supply Quality (PSQ) is a term referring to a wide variety of disturbances in electric networks either ship or continental ones (Dugan et al., 1996; Vokas et al., 1993; Bollen, 1999; Mindykowski, 2003). Thus, PSQ problems refer to deviations of electric quantities from nominal values and wave-shapes, which can cause several malfunctions, interruption or even damages of equipment and systems. Considering the advent of AES, where all equipment, including main propulsion systems, will be completely electrified, PSQ problems will be of primary importance for the safe and normal operation of any waterborne vessel.

Therefore, this paper aims primarily at making a coherent description and classification of the PSQ phenomena (causes, consequences, characteristic parameters etc.) occurred onboard highlighting their significance in the successful accomplishment of vessels' missions. In certain cases, this overview is supported by discussions of the way these issues are treated by certain related standards for shipboard installations, while where required cross references to relevant standards of continental grids is also made. 
The standards relevant to the subject of this paper are:

- $\quad$ IEEE $1159^{1}$ and IEEE Std 519-1992 (1993) on general and harmonic distortion PSQ issues respectively. These standards refer to continental grids, however, as they have recently issued, they have introduced several new aspects on PSQ terminology and problem resolution.

- IEEE $45^{2}$ and IEC-60092/101 (1994) mainly dealing with general ship network installations. Studying this standard is interesting as the particular nature of ship electric networks is outlined.

- STANAG-1008 (2004) referring to the electrical power plants in NATO naval vessels. This is a standard that has come out of USA MIL-STD-1399 (NAVY)-Section $300 \mathrm{~A}^{3}$ under the responsibility of the NATO AC/141(NG/6) SubGroup/4. This standard refers actually to normal operation of warships and has introduced a series of PSQ interesting issues.

- Classification Society Rules ${ }^{4}$ mainly referring to normal operation of electric networks of commercial ships. These rules, in general, have not taken into account the significant upcoming changes in the network field and are rather poor in stipulating standardised terminology and limitations. A worth mentioning exception is that of LRS, where in case of naval ships it makes reference to STANAG-1008.

From a certain point of view, PSQ phenomena can be classified into two main categories, i.e.:

- $\quad$ steady-state phenomena which have inherent periodicity and they are repeated on almost constant basis without significant changes (e.g., there is no decaying mechanism), such as harmonics and unbalance, while there is also a stochastic parameter included in certain cases like notching, flickering etc.

- transient-state phenomena, which are of limited duration and they are characterised by significant changes (there is definitely a decaying mechanism), such as spikes and transients like dips, swells.

It is worth noting that power quality phenomena refer to the fundamental electric supply quantities, i.e., voltage, frequency and possibly current. The first two consist the main system characteristic quantities that have to be kept intact and well within the limits set by the standards. The current on the contrary, is a quantity affecting power quality via the voltage drop on the system through the relevant impedances. Therefore, limitations on current (as considered in some standards) are necessary in order to guarantee high quality of the voltage.

This paper aims at making a succinct discussion on the most important PSQ problems. It is shown that the eventual extensive electrification of all systems aboard is expected to highlight the significance of these problems that can jeopardise the accomplishment of ships' mission. Furthermore, it is shown that the most relevant standards do not adequately cover all aspects therefore revisions are needed. The PSQ problems dealt in the paper are harmonic distortion, spikes/transients/voltage dips/Voltage swells, voltage and frequency modulation (due to pulsed loads), voltage unbalance, and leakage capacitive currents. Finally, interruptions and frequency variations are also discussed. For each power quality issue a succinct description of its 
nature and origination is made, followed by its possible adverse consequences as well as limitations set by standards, while in the end a set of mitigation measures is cited.

\section{Harmonic distortion}

Harmonic power quality refers to the existence of distorted periodic voltage or current waveforms, which, can be expressed via mathematical Fourier analysis, as the superposition of an infinite series of frequencies, the fundamental one (the so-called power frequency) and its multiples, the high-order harmonics $V_{n}$ :

$$
v(t)=\sum_{n=1}^{\infty} V_{n} \sqrt{2} \sin \left(n . \omega t+\theta_{v, n}\right) \quad i(t)=\sum_{n=1}^{\infty} I_{n} \sqrt{2} \sin \left(n . \omega t+\theta_{i, n}\right) .
$$

Harmonic distortion is mainly due to power electronic devices used to couple and control different operating voltage and frequency levels e.g., in shaft generator systems or in electric motor drives. In contradiction to other power quality problems, harmonic distortion is a steady-state phenomenon existing on a constant time basis, which means that the stresses occurred, though not severe, can eventually provoke an accumulative result often not easily explained. The impacts of harmonic voltage and/or current distortion - are Dugan et al. (1996), Vokas et al. (1993), IEEE Std 519-1992 (1993) and McGranahan (1998):

- $\quad$ extra heating losses in electric machinery and cable wiring (leading to either premature aging and de-rating of the equipment due to overheating or to extra cooling requirements)

- decrements in accuracy of measuring equipment, which are not designed for non-sinusoidal electric quantity measurements

- excitation of resonance phenomena resulting to significant over voltages and/or over currents

- false tripping of protective switchgear (e.g., fuse blowing, or incorrect thermal relays actuation)

- failure of equipment sensitive to harmonics

- Electromagnetic Interference (EMI) problems with sensitive electronic equipment (navigation, communication control and automation)

- $\quad$ erection of mechanical oscillations, vibrations, mechanical stresses and noise due to harmonic torque ripples produced.

Harmonics are treated by many standards as a voltage quality issue, as voltage can be directly controlled and regulated by the power system. On the contrary, current is determined by the various loads supplied, therefore, current quality can not be easily controlled, despite that current distortion is also reflected to voltage, via the voltage drop on circuit impedances. Hence, much attention must be paid to current quality defined by the entity of loads installed onboard or at least the major ones, i.e., those of significant power demand with respect to electric system capacity. 
Regarding appropriate indices to demonstrate the level of distortion, besides the individual voltage and current harmonics $V_{n}$ and $I_{n}$, (see equation (1)), Total Harmonic Distortion (THD) seems to be the most coherent one, expressed as the portion of high order harmonics with reference to the fundamental component:

$$
\mathrm{THD}_{V}=\frac{\sqrt{\sum_{n=2} V_{n}^{2}}}{V_{1}} \quad \operatorname{THD}_{I}=\frac{\sqrt{\sum_{n=2} I_{n}^{2}}}{I_{1}} .
$$

It is worth noting that according to the THD definition, both the fundamental component and the high order harmonics should be measured simultaneously. However, should in equation (2), the fundamental equals an average quantity over a specific time interval, then the index is called Total Demand Distortion (TDD).

In Figure 1 a comparative presentation on the voltage harmonic distortion limitations set by several standards.

Figure 1 Graphic representation of individual voltage harmonic limits set by various standards

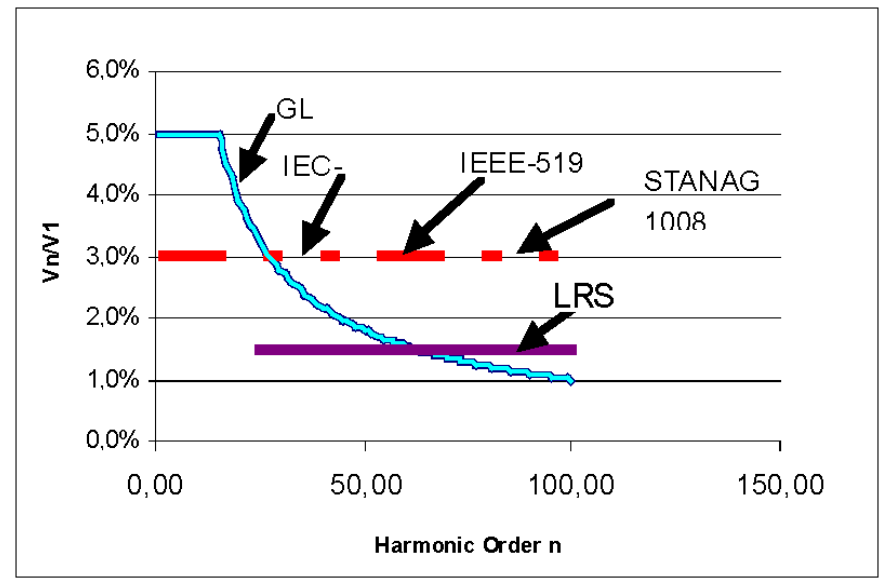

Besides the typical harmonic distortion consisting of integer multiples of multiples of the fundamental frequency and consitute the most typical type of harmonic distortion, the so-called 'interharmonics' and 'sub-harmonics', i.e., non-integer multiples and partial multiples of the fundamental frequency respectively comprise a sort of distortion not well defined or predicted.

Regarding mitigation measures for harmonic distortion problems, these comprise either intervention of appropriate filters (combinations of passive elements - reactors and capacitors - tuned at certain frequencies) or the introduction of improved switching techniques for the power converters or even the use of more complicated converter topologies (higher pulse order converters, for example 12-pulse).

Moreover, two strongly related to harmonic distortion PS-issue with inherent stochastic nature are the 'notching' and 'noise' phenomena, to which not much attention is paid by any ship Standard.

More specifically, notching is a periodic voltage disturbance caused during the normal operation of power electronics devices due to commutation, see Figure $2 .^{5}$ Three-phase converters are the most important source of voltage notching. Notching is a 
steady state phenomenon but unlike the harmonic pollution issues described previously, notching is associated with higher frequencies. This phenomenon can cause problems to electronic equipment that use zero crossings for frequency or time calculation.

Figure 2 Typical waveform with notches

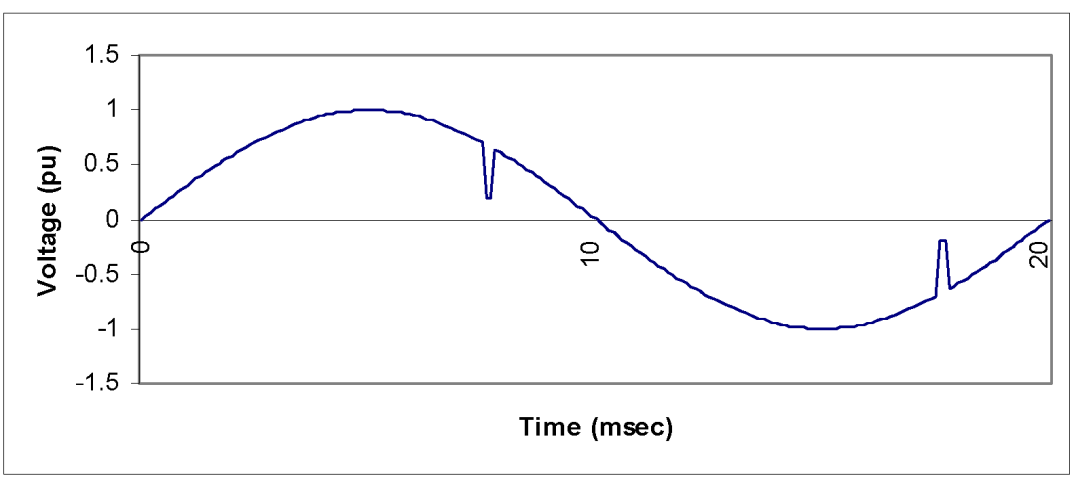

Furthermore, noise comprise signals with broadband spectral content lower than $200 \mathrm{kHz}$ superimposed upon the power system voltage or current in phase conductors, or found on neutral conductors or signal lines ${ }^{1}$ and it is caused by power electronic devices, control circuits, arcing equipment and switching power supplies. Noise disturbs electronic devices such as microcomputer and programmable controllers. Solutions to noise problems include filters, isolation transformers etc.

Harmonic and notching problems are expected to significantly increase in the AES perspective as their main causes i.e., power electronic devices are to be extensively applied onboard either for AC/DC conversion or for electric motor driving. ${ }^{5,6}$

\section{Spikes, transients, dips, swells}

Electric networks suffer from "short time duration non-periodical disturbances" of voltage and current caused by switching operations (making or breaking), short-circuits, fuse blowing- or even lightning strikes. ${ }^{7-9}$ The name of these disturbances varies depending on certain characteristics of them (e.g., transients, spikes, dips, swells etc.). ${ }^{10,11,12}$

Voltage dips are events that present a temporary decrease in the rms voltage. They are caused by an increase in current somewhere in the system (because of a short circuit or during motor starting or transformer energising due to saturation) (Styvaktakis and Bollen, 2003). A voltage swell is a temporary increase in rms voltage. Swells are usually caused by fault conditions in ungrounded systems.

Fault-induced dip magnitude depends on the impedance of the source (system's strength), system configuration, fault impedance, fault type and the distance to the fault. Fault-induced events present the most severe characteristics. Their duration depends on the protection system operation, which varies from half-cycle (fuse operation) to several cycles (operation of circuit breakers). Voltage dip and swell propagation in a system is affected by the winding connections of the transformers. Voltage dips and swells are characterised by their rms magnitude and duration. 
Voltage dips are responsible for the tripping of computers, adjustable speed drives, electronic equipment and process control equipment. Swells can be harmful for electrical insulation (Bollen, 1999). Voltage dip mitigation can be achieved with the use of energy storage devices (like a UPS) or with power electronic equipment that can compensate the partial loss of voltage (for example, dynamic voltage restorers). It is important to realise that the ability of a load to ride through a voltage dip is subject to the duration of the voltage dip that is the time the protection needs to clear a fault in the system. Therefore, faster protection operation reduces the duration of voltage dips and increases the possibility for loads to cope with this type of events (Bollen, 1999).

A transient and a spike are a sudden, non-power frequency change in voltage or current, or both. They can be unidirectional or oscillatory in polarity. Lightning and switching actions are typical causes of spikes and transients. For example a 'spike' can occur in the initial phase of the 'transient' phenomenon following the energising of a load (see Figure 3, Hatzilau and Fafalios, 1996). This energising drives the network to oscillations with the resonant frequency of the whole system. The evolution of the disturbance (waveshape, peak-value, etc.) is influenced by many parameters such as: load impedance, the elements of the Thevenin equivalent source of the supply network at the position of the load, the time instant on the voltage waveform where the energisation take place and the characteristics of the switch and the non-linear and partly statistic behaviour of the electrical characteristics of the arc.

Figure 3 Voltage transient measurement from a low voltage network

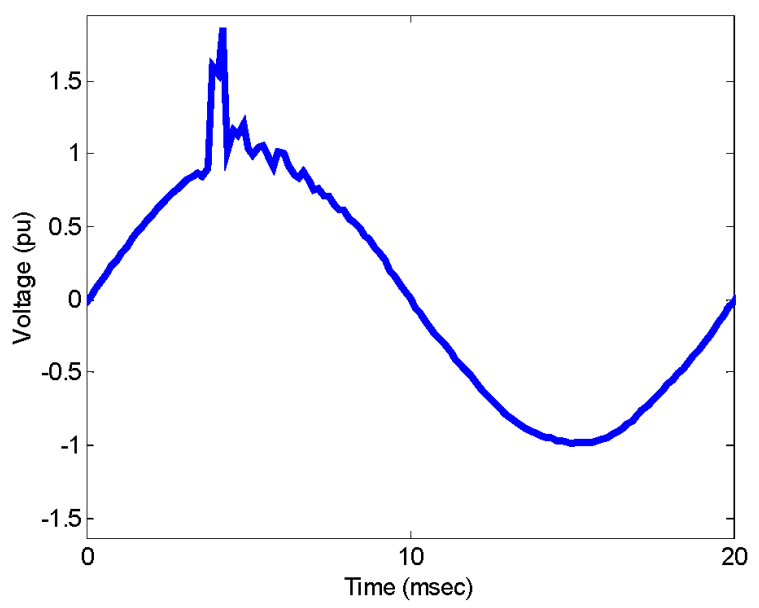

Voltage and Current spikes and transients have several adverse consequences such as equipment failure and improper operation of the entire system, like:

- insulation breakdown

- misfiring of semiconductor switches by the rate of voltage change, leading to device failures or even errors in data processing devices

- false tripping of adjustable speed drives

- regarding surge protective devices transients in voltage as well as in current are crucial. 
Spikes and Transients are characterised considering the actual values of the voltage waveform. A surge arrester can absorb the energy of a spike or a transient and it is the most typical way to protect loads from experiencing problems by this type of phenomena. Sophisticated methods can be also used in order to avoid abnormal over voltages during switching actions (for example synchronous closing - energising at zero voltage)

Considering naval standards, STANAG 1008 Ed.8 distinguishes abruptly - and in contradiction to the real natural phenomena - between 'spike' and 'transient' in the amplitude (DV) - duration (Dt) diagram. Other standards (e.g., ITIC, 2000) use an intermediate 'sloped' section of the curve, which separates the permissible and not-permissible areas in the amplitude-duration diagram. Additionally, in Ed.9 of STANAG 1008 the decisive characteristics for distinguishing transients from spikes are not clear and this may lead to confusion Figure 4.

Figure 4 ITIC compared to STANAG 1008 (dashed line) (applicable to $120 \mathrm{~V}$ equipment $-60 \mathrm{~Hz}$ )

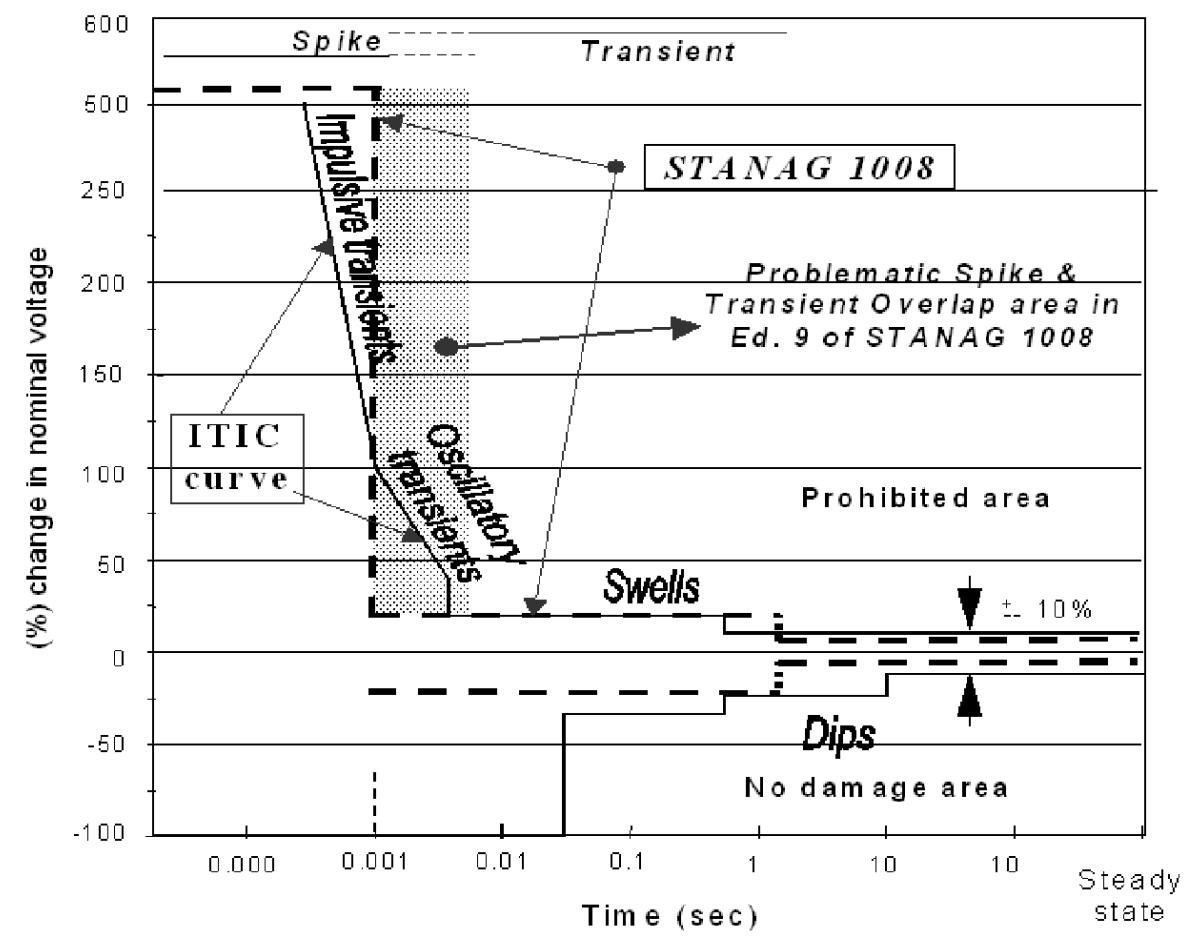

\section{Modulation/pulsed loads}

Voltage and frequency periodic or quasi-periodic variations caused by regularly or randomly repeated loading with frequency less than nominal are referred in shipboard Standards (STANAG 1008, IEEE 45) as 'modulation'. In Figure 5, voltage and frequency modulation is shown. For quantifying voltage or frequency modulation the difference between maximum and minimum value is used as a percentage of the double of the nominal value. $2 \%$ and $0.5 \%$ limits are proposed for voltage and frequency, respectively. 
In continental systems this low value systematic fluctuations of voltage are measured by the flickermeter and the phenomenon is referred to as flicker due to the effect that it has on lighting. Flicker is quantified by the use of long-term and short-term indexes, $P_{l t}$ and $P_{s t}$, respectively (IEEE 1453). ${ }^{13}$ However, modulation/flicker is not considered for frequency.

Figure 5 Voltage and frequency modulation

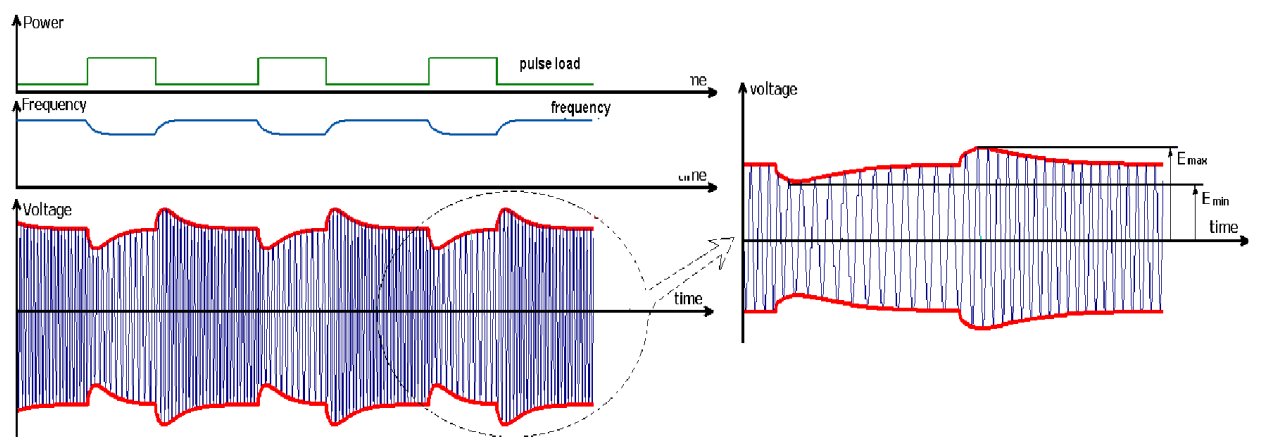

The future electric power system of naval warships in the context of the AES will supply energy to sophisticated systems for propulsion, electric guns, electric launchers, high power sensors, navigation etc. Amy et al. (2003) and Janet and Wegner (1998). ${ }^{14,15}$ Some of new naval weapon systems, referred as 'pulsed loads', require high power (in order of several GWs) for a very short interval in order of a few seconds and even milliseconds are the main cause of voltage/frequency modulation. Typical examples of pulsed loads include:

- Electromagnetic Aircraft Launch Systems (EMALS)

- $\quad$ electromagnetic guns (rail guns, coil guns, lasers, high energy microwaves)

- $\quad$ radars, sonars, communication systems etc.

Experience from power systems states that the primary effects of pulsed loading are manifested in the areas of Howard et al. (1990):

- voltage flicker

- transient stability (the ability of synchronous machines to remain in synchronism after a large disturbance)

- dynamic stability or long-term stability (the ability of a system to remain stable when generator swings are primarily dictated by the response of their control systems)

- excitation of torsional frequencies in generators.

The aforementioned may affect the operation of several subsystems of a ship such as radarscopes, communication equipment, missile guide systems weapon systems, gear systems etc. ${ }^{15}$

According to STANAG 1008, pulsed loads should not exceed the limits specified by the following equations:

$$
Q_{\text {pulse }}<0.065 \times S_{\text {supply }} \text { and } P_{\text {pulse }}<0.25 \times S_{\text {supply }} .
$$


$P_{\text {pulse, }}, Q_{\text {pulse }}:$ active, reactive power of the pulsed load

$S_{\text {suppl }}$ : full rated apparent power of the supply at the occurrence of the pulse.

Power sources for electromagnetic guns require technologies that are very different from the other applications due to very high pulse powers and very short durations (50 GW and 6-10 ms). Compensated pulsed alternators, homopolar generators, capacitor banks and flux pumps are more suitable for millisecond-long pulses. In contrast, flywheels or EMALS (120 MW, $2 \mathrm{~s}$ ) stand much closer to the commercial applications, and currently are extensively researched.

Pulsed loads integration requires an adequate and well-designed energy storage system such as:

- electrochemical: batteries and capacitors

- mechanical: flywheels

- electromagnetic: superconducting magnetic electric storage.

Concerning mitigation measures, energy storage systems (for example flywheels) can play a significant role (Amy et al., 2003; Janet and Wegner, 1998; Donaldson, 2002). One energy storage technology will not probably be the optimum solution for every application provided that power and energy densities must be adequate to achieve the power and energy levels required for naval applications within the allowable economic, size and weight constraints.

\section{Voltage unbalance}

In a symmetrical three phase system, phase voltages are equal in magnitude and their phase angle differs by $120^{\circ}$. Deviation from this symmetry (unbalance) is caused by several reasons: ${ }^{16}$

- asymmetrical distribution of single phase or two phase loads

- $\quad$ single phase generation (small photovoltaic panels, fuel cell units etc.)

- problems with joints and switching equipment (open circuits, loose connections, blown fuses etc.).

Unbalance causes problems to:

- Induction motors. The rotating magnetic field of the negative sequence component (as a result of the unbalance) is opposite to the field of the positive sequence component. Therefore the machine does not produce its full torque. Additionally, the bearings suffer from mechanical stress because of induced torque components at double system frequency, while the stator and, especially, the rotor are heated excessively (leading to faster thermal ageing). Heat results from currents induced by the fast rotating (in the relative sense) opposite/negative magnetic field, as seen by the rotor. The extensive electrification of all systems onboard according to AES concept will include the installation of increased number of electric machines increasing, thus, the system problematic operation due to voltage unbalance. 
- Synchronous generators. Phenomena similar to those described for induction machines, but mainly excess heating.

- Transformers. Stray losses in parts such as the tank are caused due to circulating zero sequence/homopolar currents in the delta winding of transformers.

- Electronic power converters which are faced with additional, uncharacteristic, harmonics. Excessive currents associated with this could lead to tripping of drive systems and thermal stress. Harmonic distortion imposed to the rest of the system is also a concern.

\section{Leakage capacitive currents}

Leakage capacitance phenomenon refers to capacitive leakage currents circulating between the main ship electric network and the ship's hull via stray equipment capacitances and/or their EMC filter input capacitances (Bal and Stephens, 1982; Dalton and Desai, 2004). ${ }^{17-19}$

Stray capacitances actually exist between any conductive elements at different potential levels and at a distance from one another, e.g., two phases or one phase and the zero potential point (by default the ideal ground, which in case of a shipboard installation is the ship's hull). In practice, however, only the capacitive elements between one phase and earth are those of significant value.

The leakage capacitive current is mainly due to the following three mutually interrelated factors:

- The most common unearthed nature of electric system which is actually earthed via the high impedance capacitances of the neutral points of wye-connected transformer/generator windings supplying energy to downstream loads (this earthing type is particularly selected in shipboard installations as it provides continuous power supply even in case of single-phase earth faults; this can not be done by low resistance in neutral earthing point).

- Stray capacitances (distributed or lumped type) of equipment such as machine windings and power distribution cables.

- Capacitances of equipment input filters mainly used for EMC improvement and harmonic distortion elimination.

In all cases, the resultant cumulative capacitance is of rather low impedance at 50/60 or $400 \mathrm{~Hz}$ operating frequency enabling, thus, the circulation of a fairly large capacitive current.

The possible consequences, most of which are of adverse nature are related to an unexpectedly large capacitive current due to the high cumulative capacitance are:

- personnel safety: as even the steady-state circulating leakage current can be dangerous or lethal for the human factor

- fuse failures or circuit breaker tripping due to the high capacitive current developed, leading either to system unbalanced operation or to complete power supply failure 
- problems with insulation monitoring system installed onboard due to unearthed system ('false monitoring signal')

- provocation of possible resonances especially in conjunction with harmonic distortion problem. ${ }^{20}$

- deterioration of harmonic power quality problems as the total harmonic impedances decrease due to the shunt capacitive susceptances offering a more conductive circulation path for harmonic currents.

However, there are also some positive consequences due to the high valued capacitance, namely the comparatively low transient overvoltages developed during switching operations, as these overvoltages are reciprocally proportional to the square root of the capacitance.

STANAG-1008 and USA-MIL-STD-1399 stipulate that the total leakage current should not exceed $20 \mathrm{~A}$, while referring to filter capacitances they should be less than $0.1 \mu \mathrm{F}$ at the $60 \mathrm{~Hz}$ and $0.02 \mu \mathrm{F}$ at the $400 \mathrm{~Hz}$ power system, respectively.

Moreover, regarding mitigation measures, it is recommended that all single-phase equipment are connected between two phases rather than one phase and the ground. Further mitigation actions include resonant earthing system via 'Petersen coils', which can counter-balance the leakage capacitive currents. Mains filters should be mounted as close as possible to power entry so that high frequency interference does not bypass the filter. To achieve higher attenuation or an increase in the effective working frequency range more complex filters can be made using more common mode or differential mode inductors or capacitors.

\section{Other PSQ issues}

Besides the aforementioned PSQ features, some additional issues i.e., power supply interruptions and power frequency variations are covered in the following.

Thus, power supply interruptions are an important aspect of power quality and it must be included in a monitoring survey with all the relevant details (cause and duration) in order to evaluate the performance of the electric system, identify the weak components, apply enforcements and select appropriate power quality mitigation equipment.

Referring to power frequency variations, one must note that power system frequency is related to the rotational speed of the generators on the system which depends on the balance between the load and the capacity of the available generation. When this dynamic balance changes, e.g., during starting-up of large power motors like those of thrusters, small changes in frequency occur. In isolated power systems, as the ones in ships, problems occur when the governor response to abrupt load changes is not adequate to regulate within the bandwidth required by frequency sensitive equipment (example: processes that use power frequency for timing).

\section{Conclusions}

In this paper, an overview is presented of power quality issues seen from the ship power system point of view considering the forthcoming complete electrification of all systems 
onboard (AES). Thus, the different aspects (origin, characteristics, effect on loads, characterisation methods) of several power quality phenomena are summarised. These phenomena are:

- harmonics (an important issue due to the increasing use of power electronics)

- short duration voltage events (spikes, transients, dips and swells)

- voltage unbalance (a threat for the operation of induction motors).

Furthermore, two topics with power quality implications are identified: voltage quality problems due to pulsed loads (which impose significant stress on the power system) and leakage capacitive currents (a distinctive characteristic of ships with particular effect on personnel safety, short-circuit faults, harmonic distortion, transients and EMC).

Power quality is a factor of increasing importance on the design and operation of naval electrical power system. The increasing needs of modern ships (advanced propulsion systems, modern onboard weapons etc.) require studies with respect to the distinctive characteristics of ships and measurements surveys to depict power quality on existing systems.

Finally, in this paper, it is shown that:

- the complete electrification of ships raises important issues in terms of PSQ especially with respect to the new propulsion systems

- standards and regulations for ships need amendments incorporating, on the one hand experience gained in terrestrial systems, as well as dedicated research work performed in the field of AES.

\section{Acknowledgements}

The work of this paper is part of the research project 'Pythagoras-II' within the "Operational Programme for Education and Initial Vocational Training - EPEAEK-II"frame. The Project is co-funded by the European Social Fund (75\%) and Greek National Resources (25\%).

\section{References}

Amy, J.V. Clayton, D.H. and Mc Coy, T.J. (2003) 'The evolving nature of loads in an electric warship', AES 2003, 13-14 February, UK.

Bal, R. and Stephens, G.W. (1982) 'Neutral earthing of marine electrical power systems', Trans I Mar E (TM), Paper No. 32, Vol. 95, pp.1-11.

Bollen, M.H.J. (1999) Understanding Power Quality Problems: Voltage Sags and Interruptions, IEEE Press, NY.

Dalton, T.C. and Desai, B. (2004) 'All electrical systems are grounded - the difference is in the type and degree of isolating impedance', INEC2004, Marine Technology in transition, Amsterdam, 16-18 March.

Donaldson, A.J. (2002) Energy Storage - New Technologies and New Roles, INEC, BSc, MSc, MINucE, Ceng, 23-5 April, SECC, Glasgow, UK.

Janet, D. and Wegner, L (1998) Long Term Scientific Studies/47 on Electric Power Systems, NATO Research and Technology Organization, 17 April, Brussels (Belgium). 
Dugan, R. McGranaghan, M. and Beaty, H.W. (1996) Electrical Power Systems Quality, McGraw-Hill, New York.

European Standard EN-50160 (1994) Voltage Characteristics of Electricity Supplied by Public Distribution Systems, CENELEC, Brussels, Belgium.

Hatzilau, I.K. and Fafalios, M.E. (1996) 'Phenomenological investigation of voltage spikes introduced by energizing low power electronic equipment', Proceedings Int. Conf. on 'Circuits, Systems and Computers '96', HNA, Piraeus, Vol. 2, 15-17 July, pp.513-520.

IEC-60092/101 (1994) Electrical Installation in Ships - Definitions and General Requirements, International Electrotechnical Committee (IEC), Zurich, Switzerland.

IEEE Std 519-1992 (1993) IEEE Recommended Practice and Requirements for Harmonics Control in Electrical Power Systems, IEEE, New York, 12 April.

McGranahan, M. (1998) 'Overview of the guide for applying harmonic limits on power systems-IEEE 519A', Proceedings of 8th International Conference of Harmonics and Quality Power, Athens (Greece), 16-18 October, pp.462-469.

Mindykowski, J.K. (2003) Assessment of Electric Power Quality in Ship Systems Fitted with Converter Subsystems, Shipbuilding and Shipping Ltd, Gdansk, ISBN 83-88621-07-6.

Smolleck, H.A., Ranade, S.J., Prasad, N.R. and Velasco, R.O. (1990) 'Effects of pulsed - power loads upon an electric power grid', IEEE/PSS 1990 Sumner Meeting, Minneapolis, Minnesota, 15-19, July.

STANAG 1008 (1994) Characteristics of Shipboard Electrical Power Systems in Warships of the North Atlantic Treaty Navies, 8th ed., 21 February, Brussels, Belgium.

STANAG 1008 (2004) Characteristics of Shipboard Electrical Power Systems in Warships of the North Atlantic Treaty Navies, 9th ed., 21 February, 1994/9th ed., 24 August, Brussels, Belgium.

Styvaktakis, E. and Bollen, M.H.J. (2003) 'Signatures of voltage dips: transformer saturation and multistage dips', IEEE Trans. on Power Delivery, Vol. 18, No. 1, January, pp.265-270.

TC3 of the Information Technology Industry Council (ITIC) (2000) ITIC (CBEMA) Curve, www.itic.org

Vokas, G. Gazithellis, D. Katsikaris, C. and Peponis, G. (1993) Electric Power Quality, Technical Chamber of Greece, Athens, May (in Greek).

\section{Notes}

${ }^{1}$ IEEE Std 1159-1995, IEEE Recommended Practice for Monitoring Electric Power Quality.

${ }^{2}$ IEEE Standard 45-1998, IEEE Recommended Practice for Electrical Installations on Shipboard.

${ }^{3}$ USA MIL-STD-1399 (NAVY), Interface Standard for Shipboard Systems - Section 300A

- Electric Power, Alternating Current.

${ }^{4}$ Rules and Regulations of Classification Societies.

${ }^{5}$ NATO AC/141(SG/6)SG/4 GERMANY paper (02)96/10-03.04.96: STANAG 1008, Harmonic Distortion, Compilation of Replies to Questionnaire.

${ }^{6} \mathrm{NATO}$ AC/141(SG/6)SG/4 GREECE paper (03)00/28-03.04.00, Interpretation of Current Distortion Limits of STANAG 1008 Ed. 8.

${ }^{7}$ IEEE 'Surge-Trilogy' about 'surges': IEEE Std C62.41.1 ${ }^{\mathrm{TM}}-2002$, IEEE Std C62.41.2 ${ }^{\mathrm{TM}}-2002$ and IEEE Std C62.45.1 ${ }^{\mathrm{TM}}-2002$.

${ }^{8} \mathrm{http} / / /$ www.eeel.nist.gov/817/817g/spd-anthology/

${ }^{9}$ NATO AC/141(SG/6)SG/4, U.K., ADLPS/7/9/16-Sept.87 and 91/15-03.06.91, Discussion Paper on Voltage Spikes on Shipboard Power Supply Systems.

${ }^{10}$ IEEE Std. 112-1991, IEEE Standard test procedure for polyphase induction motors and generators. 
${ }^{11}$ IEEE Std. 100-1996, IEEE Standard Dictionary of Electrical and Electronic Terms.

${ }^{12} \mathrm{NATO}$ AC/141(SG/6)SG/4 GREECE paper 05/99(09) - 12.01.99, Voltage Spikes and Transients (STANAG 1008) - Summary of Answers.

${ }^{13}$ IEEE Std 1453-2004, Recommended Practice for Measurement and Limits of Voltage Fluctuations and Associated Light Flicker on AC Power Systems (Adoption of CEI/IEC 61000-4-15:1997+A1: 2003).

${ }^{14}$ http://www.onr.navy.mil, US Office Naval Research

${ }^{15} \mathrm{NATO}$ AC/141(SG/6)SG/4, GREECE, 17(GR)03.01 - 14.03.2003. AES-Chapter 8, PULSED LOADS, Summary of Answers.

${ }^{16}$ NATO AC/141(SG/6)SG/4, FRANCE, 91/09-28.10.91, Stanag 1008 - Taux de desequilibre d' un reseau triphase (Document Electricite de France d'aout 1984, J.P. Meyer, Contribution a la determination du taux de desequilibre d' un reseau triphase).

${ }^{17}$ NATO AC/141(SG/6)SG/4, UK, 92/19-01.10.92, Revised summary of replies received to UK questionnaire on the use of gapacitive EMC filters.

${ }^{18}$ NATO AC/141(SG/6)SG/4, GERMANY, (45)93/22-11.11.93, Leakage capacitance.

${ }^{19}$ NATO AC/141(SG/6)SG/4, GERMANY, (06)97/14, Leakage capacitance. Effects of capacitance between line and earth.

${ }^{20}$ NATO AC/141(SG/6)SG/4, THE NETHERLANDS, 09(NL)99/03, 1-3-1999, Harmonic Currents and Leakage Capacitance.

\section{Bibliography}

Bachman, L., Gullberg, M., Strickler, F. and Sachs, H. (1981) 'An assessment of shipboard power line transients', Proceedings, International IEEE EMC Symposium, August, Las Vegas, USA.

Bollen, M.H.J. (2002) 'Definitions of voltage unbalance', IEEE Power Engineering Review, Vol. 22, No. 11, November, pp.49, 50.

Cannova, S.F. (1973) 'Short-time voltage transients in shipboard electrical systems', IEEE IAS 1972 Annual Meeting Conf. Rec. and IEEE Transactions IA-9, No. 5, September-October, pp.533-538.

Electric power supply quality concepts for the All Electric Ship (AES) (2006) Proceedings of 2006 World Marine Transport Technology Conference-INEC2006, March, London.

Flower, J.O. and Hodge, C.G. (2004) 'Stability and transient-behavioural assessment of power-electronics based dc-distribution systems', IASME Transactions, Vol. 1, No. 2, April, pp.388-393.

Hatzilau, I.K., Magoulas, A., Perros, S., Kavoulakos, D., Sakiotis, Christofis, E., Martinos, F. and Prousalidis, J. (2002) 'Harmonic power quality on naval ships electric systems (standards overview - field measurements)', Proceedings of 3rd Mediterranean Conference and Exhibition on Power Generation Transmission Distribution and Energy Conversion (MEDPOWER 2002), 4-6 November, Athens, Greece, Paper No. 082.

Hatzilau, I.K., Prousalidis, J., Styvaktakis, E. and Sofras, E. (2005) 'Voltage and current spikes and transients - power supply quality aspects for the AES', Proceedings of 5th Int. Symposium AES 2005 'Civil or Military AES', 13-14 October, Paris, Paper No. 19.

Hatzilau, I.K., Prousalidis, J., Styvaktakis, E., Kanellos, F., Perros, S. and Sofras, E. (2006) 'Electric power supply quality concepts for the All Electric Ship (AES)', Proceedings of 2006 World Marine Transport Technology Multi-Conference (WMTC-INEC2006), March, London, Paper No. 44.

Key, T., Mansoor, A. and Martzloff, F.D. (1996) 'No joules for surges: relevant and realistic assessment of surge stree threats', 7th International Conference on Harmonics and Quality of Power, Las Vegas, 16-18 October, pp.67-72. 
Lindes, G., Mansor, A., Martzloff, F.D. and Vannoy, D. (1997) 'Surge recordings that make sense: joules deposition: yes! - 'Joule content': never!', Proceedings, PQA'97, August, Colombus-Ohio, USA.

Martzloff, F.D.S. (1996) 'Surge recordings that make sense: shifting focus from voltage to current measurements', Proceedings, EMC'96 ROMA Symposium, September, Roma Italy.

Pillay, P. and Manyage, M. (2001) 'Definitions of voltage unbalance', IEEE Power Engineering Review, Vol. 22, No. 5, May, pp.50, 51.

Prousalidis, J., Hatzilau, I.K. and Perros, S. (2003) 'Harmonic electric power quality concepts for the electrified ships (AES)', Proceedings AES2003 Broadening the Horizons, 13-14 February, Edinburgh, pp.279-290.

Prousalidis, J., Perros, S., Hatzilau, I.K., Buchanan, P. and Muthumuni, D. (2004) 'Introducing a COTS simulation tool for ship electric power quality studies', INEC 2004, 16-18 March, The Netherlands.

Robert, A. and Marquet, J. (1992) Assessing Voltage Quality with Relation to Harmonics, Flicker and Unbalance, WG 36.05, CIGRE 92, pp.36-203. 